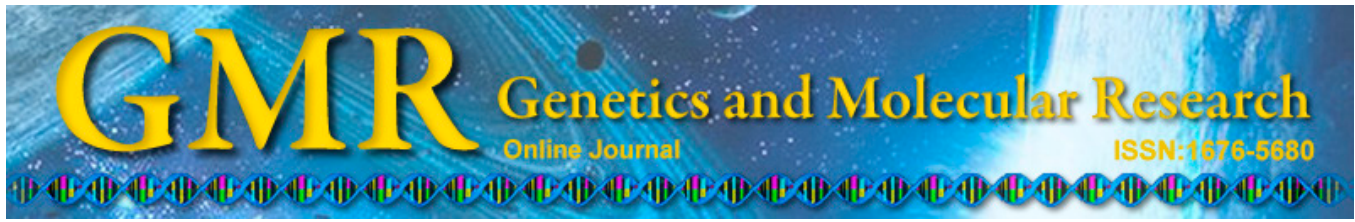

\title{
Study of lipid metabolism-related genes as candidate genes of sexual precocity in Nellore cattle
}

\author{
M.M. Dias, F.R.P. Souza, L. Takada, F.L.B. Feitosa, R.B. Costa, \\ I.D.P.S. Diaz, D.F. Cardoso, R.L. Tonussi, F. Baldi, \\ L.G. Albuquerque and H.N. Oliveira \\ Departamento de Zootecnia, \\ Universidade Estadual Paulista "Júlio de Mesquita Filho", Jaboticabal, \\ SP, Brasil \\ Corresponding author: M.M. Dias \\ E-mail: marina.mortati@gmail.com
}

Genet. Mol. Res. 14 (1): 234-243 (2015)

Received June 14, 2014

Accepted December 6, 2014

Published January 16, 2015

DOI http://dx.doi.org/10.4238/2015.January.16.7

ABSTRACT. The objective of this study was to identify associations
between known polymorphisms in genes related to adipose tissue and
sexual precocity in Nellore cattle. A total of 1689 precocious and non-
precocious heifers belonging to farms participating in Conexão Delta G
breeding program were studied. SNPs from the Illumina High-Density
Bovine SNP BeadChip were used. This chip contains 777,000 SNPs
located within the region of the candidate genes at a distance of up to 5
kb, considering that linkage disequilibrium (LD) exists at this distance.
Linear models were used for statistical analysis. The fastPHASE and
GenomeStudio programs were used for haplotype reconstruction and
LD analysis based on $\mathrm{r}^{2}$ statistics. Fifty-seven candidate genes and 443
SNPs were analyzed: among the latter, 370 SNPs formed 83 haplotypes,
while the remaining SNPs were studied separately. Statistical analysis
showed that only three haplotypes, one haplotype consisting of two SNPs
located in the FABP4 gene and two haplotypes consisting of four and 
two SNPs located in the PPP3CA gene, had a significant effect on sexual precocity at $\mathrm{P}<0.05$. It can be concluded that the FABP4 and PPP $3 C A$ genes influence sexual precocity and may therefore be used in selection programs designed to improve sexual precocity in Nellore cattle.

Key words: $F A B P 4$; Genotyping; $P P P 3 C A$; SNPs

\section{INTRODUCTION}

Nellore cattle were introduced to Brazil in 1875 . Today, the country possesses the largest commercial Nellore herd, with more than 185 million heads, and has the highest slaughter rate in the world (Anualpec, 2013). Approximately $80 \%$ of the Brazilian cattle herd consists of Zebu breeds, which are more adapted to the tropical environment, mainly because of their tolerance to heat, resistance to parasites, and productivity in this environment (Lenstra and Bradley, 1999; Chan et al., 2010). However, one of the problems of Brazilian beef cattle farming is the low sexual precocity of the herd. The mean age at puberty of Zebu heifers is 22 to 36 months (Souza et al., 1995). The production of beef cattle depends on their reproductive performance, a trait that interferes with the efficiency and profitability of this activity (Phocas et al., 1998).

Early pregnancy is a binary trait, i.e., a value of 1 is attributed for success and 0 for failure. The heritability of this trait is moderate to high, ranging from 0.45 to 0.52 in Nellore heifers evaluated at 16 months of age (Silva et al., 2005; Shiotsuki et al., 2009; Boligon et al., 2011). In addition, this trait is difficult to select mainly because it is expressed only in females already at the onset of reproductive activity. Therefore, several studies have sought to identify molecular markers for early pregnancy (Hastings et al., 2006; Islam et al., 2009; Fortes et al., 2012).

There is strong evidence that the onset of puberty is related to growth rate and the amount of body fat. Nellore heifers that are heavier at 12 and 18 months go into first heat at a younger age (Alencar et al., 1987). Recent studies in humans have shown that girls with a relatively higher body mass index are more likely to menstruate early (Kaplowitz, 2008; Wagner et al., 2012). In addition to the correlation of weight gain with sexual precocity, adipose tissue has been identified as the main site of metabolism of steroid hormones (Siiteri, 1987), a factor related to the onset of reproductive activity.

Commercially available high-density DNA microarrays enable genotyping of Nellore cattle using 450,000 single-nucleotide polymorphisms (SNPs) distributed across all autosomes, which can be used to identify quantitative trait loci (QTL) in genome-wide association studies. However, the enormous number of statistical tests applied in those studies reduces the power of the test when the number of samples available is not sufficiently large, especially if several traits are studied and tested simultaneously (de los Campos et al., 2010). Thus, when the number of samples is small, an alternative is to identify statistical associations considering a smaller number of SNPs located in regions that correspond to known genes and whose products are known a priori to interfere with physiological processes that are related to one or more specific traits. Despite the smaller number of tests, different SNPs can be tested for association with different characteristics, so that the power of the test for each characteristic will be increased considerably. 
There are several known lipid metabolism-related genes that may interfere with the development of sexual precocity in mammals. For some of these genes, studies using molecular markers have permitted the demonstration of a significant effect on sexual precocity. We therefore selected a panel of high-density SNPs located in intron and exon regions of 57 candidate genes related to lipid metabolism and adipose tissue in order to identify associations between these SNPs and early pregnancy in Nellore cattle.

\section{MATERIAL AND METHODS}

\section{Animals and sample collection}

Data from 1689 precocious and non-precocious heifers belonging to farms participating in Conexão Delta $\mathrm{G}$ breeding program were used. Of these females, $25.82 \%$ were precocious. Skin samples were collected from the tail of females aged 14-16 months during the breeding seasons of 2008 and 2009. The samples collected were placed in envelopes, identified, and stored at $4^{\circ} \mathrm{C}$ until DNA extraction.

In the herds participating in Conexão Delta $\mathrm{G}$ program, an anticipated breeding season is performed between February and April for heifers aged 14 to 16 months, which lasts 60 days. All heifers are exposed to breeding, irrespective of weight and body condition. The mating systems used are artificial insemination, controlled mating, and multiple bulls, with a sire:cow ratio of 1:50. Pregnancy of the heifers is evaluated by rectal palpation approximately 60 days after the end of the anticipated breeding season. Heifers that did not conceive during the anticipated breeding season are used in another breeding season at 2 years of age. The birthing seasons of the calves are concentrated between August and October and between November and January. The calves are kept with their mothers on pasture until 7 months of age. Criteria for culling of females in the herd are reproductive failure before 2 years of age, reproductive failure in the following years, and low progeny performance. A small percentage is culled due to sanitary problems.

\section{Extraction and quantification of DNA}

The laboratory analyses were carried out at Marcos Antônio Giannoni Laboratory of Molecular Genetics, Department of Animal Breeding, School of Agricultural and Veterinary Sciences, UNESP, Jaboticabal, SP, Brazil. DNA was extracted from the hair follicles collected from the tail of the animals using the phenol-chloroform-isoamyl alcohol method (Sambrook et al., 1989). The quantity and quality of the extracted DNA were evaluated using a spectrophotometer (NanoDrop 1000, Thermo Scientific, USA).

\section{Candidate genes}

Fifty-seven candidate genes (Table 1) encoding substances that are produced, secreted or somehow influence lipid metabolism and adipose tissue, and that have been described to influence fertility traits, were analyzed.

The genes were divided into classes of main activity, including lipid metabolism, white adipose tissue, adipocyte metabolism, and adipogenesis. The class of lipid metabolismrelated genes included those involved in the digestion of lipids into fatty acids, intracellular 
transport, oxidation in mitochondria, and biosynthesis. The class of white adipose tissuerelated genes comprised those that influence the storage of triacylglycerol, responsible for energy balance, and secreted substances. The class of adipocyte metabolism-related genes included those involved in lipogenic and lipolytic activities. Finally, the class of adipogenesisrelated genes comprised genes involved in the differentiation of adipose tissue.

\begin{tabular}{|c|c|c|c|}
\hline Main activity & Gene & Chromosome & Location \\
\hline \multirow[t]{10}{*}{ Lipid metabolism } & $A C A D L$ & 2 & $98416820-98456944$ \\
\hline & $A C O X 1$ & 19 & $56300362-56321420$ \\
\hline & $A D R B 3$ & 27 & $32912524-32915668$ \\
\hline & DGAT 1 & 14 & $1795425-1804838$ \\
\hline & FASN & 19 & $51384922-51403614$ \\
\hline & $L L P H$ & 5 & $47901612-47905608$ \\
\hline & $S C D$ & 26 & 21137945-21148317 \\
\hline & $U C P-1$ & 17 & $17467450-17473934$ \\
\hline & $U C P-2$ & 15 & $54196170-54202633$ \\
\hline & $U C P-3$ & 15 & $54213566-54224046$ \\
\hline \multirow[t]{15}{*}{ White adipose tissue } & $A D I P O Q$ & 1 & $81,006,597-81,018,375$ \\
\hline & $A G T$ & 28 & $46147260-46156094$ \\
\hline & AGTRAP & 16 & $42806428-42825905$ \\
\hline & Apo-E & 18 & $53040105-53042792$ \\
\hline & $C F D$ & 7 & $45030310-45032846$ \\
\hline & $G H-1$ & 19 & $48768618-48772014$ \\
\hline & $H G F$ & 4 & $39116167-39197870$ \\
\hline & $I G F 1$ & 5 & 66532879-66604699 \\
\hline & IL 6 & 4 & 31578311-31582679 \\
\hline & Lep & 4 & 93249874-93266624 \\
\hline & MIF & 17 & 73273379-73274171 \\
\hline & $N A M P T$ & 4 & $47594642-47635332$ \\
\hline & RETN & 7 & $17737516-17738903$ \\
\hline & SERPINE1 & 25 & $36198554-36206859$ \\
\hline & $T N F$ & 23 & $27533901-27536674$ \\
\hline \multirow[t]{12}{*}{ Adipocyte metabolism } & $A D A$ & 13 & $73750479-73773897$ \\
\hline & $C C K$ & 22 & $15190717-15196325$ \\
\hline & $E G F$ & 6 & $16565618-16669065$ \\
\hline & FABP3 & 2 & $122723225-122783830$ \\
\hline & FABP4 & 14 & $46833665-46838053$ \\
\hline & GAST & 19 & $42565344-42567655$ \\
\hline & $G C G$ & 2 & $34398011-34408393$ \\
\hline & $G I P$ & 19 & 38202539-38207784 \\
\hline & $L P L$ & 8 & 67481089-67487742 \\
\hline & $N P P A$ & 16 & $42712138-42713218$ \\
\hline & PPARa & 5 & $117150468-117233112$ \\
\hline & PPARy & 22 & $57367072-57432321$ \\
\hline \multirow[t]{17}{*}{ Adipogenesis } & $B R A F$ & 4 & $104875266-105031758$ \\
\hline & CEBPA & 18 & $43928610-43929840$ \\
\hline & DLK1 & 21 & $67274800-67283089$ \\
\hline & GRB2 & 19 & $56754112-56818430$ \\
\hline & MAPK1 & 17 & 74016491-74033720 \\
\hline & $M A P K 3$ & 25 & $26437044-26444129$ \\
\hline & $M Y C$ & 14 & $13769242-13774438$ \\
\hline & PCK1 & 13 & 59144588-59150714 \\
\hline & PLIN2 & 8 & $25129178-25137854$ \\
\hline & РPР $3 C A$ & 6 & $24812739-25136267$ \\
\hline & PRKACA & 7 & $12693767-12712110$ \\
\hline & $R A C 2$ & 5 & $76033363-76050188$ \\
\hline & RARRES2 & 4 & $113564406-113567492$ \\
\hline & $R X R B$ & 23 & $7321254-7326765$ \\
\hline & SPPI & 6 & $38120578-38127541$ \\
\hline & $T G$ & 14 & $9296197-9508938$ \\
\hline & TP53 & 19 & 27985494-27997841 \\
\hline
\end{tabular}




\section{SNP panel and genotyping}

For analysis of the candidate genes (Table 1), SNPs of the Illumina High-Density Bovine SNP BeadChip (770,000 SNPs), which are in linkage disequilibrium (LD) with these genes, were evaluated. The SNPs were chosen based on the position of the gene in the genome, assessed by evaluating the gene in GenBank (2014), and the position of the SNPs in the Illumina panel. All SNPs located at a distance of up to $5 \mathrm{~kb}$ from the genes proposed were selected. This chip provides uniform coverage, with an average distance between markers of $5 \mathrm{~kb}$ and an average minor allele frequency (MAF) of 0.25 (Illumina ${ }^{\circledR}$ SNP Genotyping) for taurine breeds.

Genotyping was performed according to the Illumina Infinium ${ }^{\circledR}$ II Assay Multi-Sample protocol using the HiScan ${ }^{\mathrm{TM}}$ SQ System. A total of 1689 precocious and non-precocious heifers were genotyped. To ensure the quality of the samples in the analyses, the GenomeStudio program (Illumina) was used to eliminate samples with a call rate less than $90 \%$. SNPs with an MAF less than 0.05 , a genotyping rate (call frequency) $<0.9$, and a $\mathrm{P}$ value for the test of Hardy-Weinberg equilibrium less than 0.001 were also eliminated.

The Genome Studio ${ }^{\circledR}$ software (Illumina) was also used to generate the files containing the data for each SNP of each animal using the Illumina TOP/BOT system.

\section{Haplotype reconstruction}

After the SNPs were identified in the region of the genes, the regions selected were analyzed using the fastPHASE program (Scheet and Stephens, 2006) for haplotype reconstruction. The results were then entered into the Haploview v4.1 program (Barrett et al., 2005) to estimate the LD between SNP pairs based on $\mathrm{r}^{2}$ statistics (Hill and Robertson, 1968) and to obtain the patterns of alleles of each haplotype. SNPs that were not part of any haplotype were considered to be separate markers.

\section{Statistical analysis}

The trait used for statistical analysis was early heifer pregnancy, which is a binary trait, obtained for all heifers that have been exposed to sire at 14-16 months in the anticipated breeding season. Pregnancy diagnosis by rectal palpation was performed in all heifers 45 days after the end of breeding season and a value of 1 was assigned to heifers that were pregnant, and a value of 0 to those that were not.

Although the trait shows a binary distribution, linear models were used for this analysis because they permit easier implementation and interpretation of the results. Therefore, a mixed linear model was used to evaluate the association of each separate SNP or haplotype with the trait of interest.

For all markers, the analysis model included the fixed effect of contemporary group and the random effect of father of the animal (sire effect). The contemporary group was defined by farm, year, and month of birth of the animal. An identification code for the father was generated for each animal with an unknown father (phantom parents) to permit analysis using the chosen software.

The SNP blocks forming the haplotypes were defined using the algorithm of Gabriel et al. (2002), which takes into consideration the confidence interval for D' statistics implemented in the Haploview software. In the analyses using separate SNPs, the number of copies 
of the most frequent allele present in the genotype of the animal was included as a covariate. In the case of segments in which the presence of haplotypes could be detected, analysis was performed considering the haplotype-forming SNP block. Also in this last case, variables containing the number of copies of each allele detected in the population, except for the least frequent, were included as covariates. The analysis model can be written as follows:

$$
y_{i j k}=G C_{i}+s_{j}+\sum_{1=1}^{\mathrm{n}-1} \mathrm{~b}_{1} \mathrm{x}_{\mathrm{ijkl}}+e_{i j k}
$$

where, $y_{\mathrm{ij \textrm {k }}}$ is the observed value of the trait studied for the $k^{\text {th }}$ animal, born to the $j^{\text {th }}$ sire in the $j^{\text {th }}$ contemporary group; $G C_{i}$ is the fixed effect of the $i^{\text {th }}$ contemporary group; $s_{\mathrm{j}}$ is the random effect of the $i^{\text {th }}$ sire; $b_{1}$ is the regression coefficient of the number of copies of the $l^{\text {th }}$ allele on the trait studied; $x_{\mathrm{ijkl}}$ is the number of copies of the $l^{\text {th }}$ allele in the animal; $e_{\mathrm{ijk}}$ is the random error, and $n$ is the number of alleles for the marker analyzed.

All analyses were performed using the Mixed Procedure of the SAS ${ }^{\circledR}$ package. Bonferroni's correction for multiple comparisons was applied to guarantee maintenance of the error rate in the statistical tests. The allele and genotype frequencies for each polymorphism were calculated as described by Weir (1996).

\section{RESULTS}

\section{DNA extraction and genotyping}

The quality of the DNA extracted was excellent, with more than $97 \%$ of samples presenting a concentration higher than $100 \mathrm{ng} / \mu \mathrm{L}$ and a $260 / 280$ ratio of 1.8 to 2.0 (Table 2), permitting the successful use of the material for genome analysis.

Table 2. Mean, maximum and minimum concentration, and 260/280 ratio of DNA extracted from hair follicles of cattle using the phenol-chloroform-isoamyl alcohol method and quantified using a NanoDrop ${ }^{\circledR}$ spectrophotometer.

\begin{tabular}{lcc}
\hline & Concentration $(\mathrm{ng} / \mu \mathrm{L})$ & $260 / 280$ ratio \\
\hline Mean & 525.90 & 1.94 \\
Maximum & 2798.45 & 2.01 \\
Minimum & 85.12 & 1.79 \\
\hline
\end{tabular}

After genotyping, samples with a call rate less than $90 \%$ were eliminated. Despite the excellent quality of the DNA extracted, 20 samples were excluded due to a low call rate. Since DNA extraction was performed using the phenol-chloroform-isoamyl alcohol method, it is possible that protein was extracted simultaneously from the hair follicles, interfering with the reading of the sample.

\section{Selection of SNPs and haplotype formation}

Among the 777,000 SNPs, 480,556 (61.9\%) had a call rate $\geq 90 \%$, MAF $>0.05$, and 
a $\mathrm{P}$ value for the test of Hardy-Weinberg equilibrium $>0.001$. Using another sample from the same herd, Espigolan et al. (2013) selected 57.5\% SNPs according to the same criteria. The SNP genotyping panels were developed based on the genome of different breeds, mainly taurine breeds, but also Zebu breeds. The markers are therefore more informative for taurine than for Zebu animals, which carry various alleles with low MAF (Matukumalli et al., 2009).

The number of SNPs found in each region of the candidate genes ranged from 0 to 73 (Table 3). The haplotypes consisted of 2 to 16 SNPs. According to Zhang et al. (2003), no pattern exists for the number of SNPs per haplotype in humans.

\begin{tabular}{|c|c|c|c|c|c|}
\hline Gene & No. of SNPs & Gene & No. of SNPs & Gene & No. of SNPs \\
\hline$A C A D L$ & 13 & GAST & 6 & PLIN2 & 1 \\
\hline$A C O X I$ & 10 & $G C G$ & 2 & PPARa & 14 \\
\hline$A D A$ & 19 & $G H-1$ & 3 & PPARy & 16 \\
\hline$A D I P O Q$ & 4 & $G I P$ & 1 & PPPЗСA & 73 \\
\hline$A D R B 3$ & 1 & GRB2 & 6 & PRKACA & 2 \\
\hline$A G T$ & 4 & $H G F$ & 12 & $R A C 2$ & 5 \\
\hline AGTRAP & 15 & $I G F 1$ & 3 & RARRES2 & 2 \\
\hline Apo-E & 0 & IL 6 & 4 & $R E T N$ & 1 \\
\hline$B R A F$ & 8 & Lep & 12 & $R X R B$ & 1 \\
\hline$C C K$ & 5 & $L L P H$ & 1 & $S C D$ & 4 \\
\hline CEBPA & 0 & $L P L$ & 9 & SERPINE1 & 0 \\
\hline$C F D$ & 3 & MAPKI & 4 & $S P P I$ & 2 \\
\hline$D G A T 1$ & 2 & MAPK3 & 0 & $T G$ & 72 \\
\hline$D L K 1$ & 2 & $M I F$ & 1 & $T N F$ & 7 \\
\hline$E G F$ & 35 & $M Y C$ & 3 & TP53 & 0 \\
\hline$F A B P 3$ & 15 & NAMPT & 9 & $U C P-1$ & 9 \\
\hline FABP4 & 3 & NPPA & 0 & $U C P-2$ & 5 \\
\hline FASN & 0 & PCK1 & 3 & $U C P-3$ & 5 \\
\hline
\end{tabular}

\section{Statistical analysis}

Statistical analysis following Bonferroni's correction revealed that only one haplotype located in the FABP4 gene and two haplotypes located in the PPP $3 C A$ gene had a significant effect $(\mathrm{P}<0.05)$ on sexual precocity in Nellore cattle. The remaining separate SNPs and haplotypes studied had no significant effect on the trait evaluated, including haplotype-forming and non-haplotype-forming SNPs in the FABP4 and PPP $3 C A$ genes. Tables 4 and 5 show the alleles found in the herd studied according to the Illumina ${ }^{\circledR}$ Top/Bot designation (Illumina Technical Support, 2006).

Table 4. Frequency, average effect, and respective standard error of haplotype alleles located in the FABP4 gene.

\begin{tabular}{lcccc}
\hline Allele & Bases of the SNPs & Frequency & Average effect & Standard error \\
\hline Allele 1 & TT & 0.527 & 0.0465 & \pm 0.0365 \\
Allele 2 & CT & 0.372 & 0.1281 & \pm 0.0391 \\
Allele 3 & CC & 0.100 & -0.1746 & \pm 0.0551 \\
\hline
\end{tabular}

The significant haplotype located in the FABP4 gene contained SNPs at positions 46833778 and 46837361 (HD 1400013256, and HD 1400013257). The first significant haplo- 
type located in the PPP3CA gene contained SNPs at positions 24944828, 24949691, 24955087, and 24960820 (HD 0600006867, HD 0600006868, HD 0600006869, and HD 0600006870, respectively). The second significant haplotype located in the PPP3CA gene contained SNPs at positions 25042950 and 25047519 (HD 0600006894 and HD 0600006895).

\begin{tabular}{|c|c|c|c|c|}
\hline Allele & Bases of the SNPs & Frequency & Average effect & Standard error \\
\hline \multicolumn{5}{|c|}{ Haplotype 1} \\
\hline Allele 1 & ACAT & 0.086 & 0.090 & \pm 0.0539 \\
\hline Allele 2 & GTGC & 0.553 & 0.1841 & \pm 0.0620 \\
\hline Allele 3 & GCGT & 0.276 & -0.0292 & \pm 0.0880 \\
\hline Allele 4 & GTGT & 0.082 & -0.2448 & \pm 0.0893 \\
\hline \multicolumn{5}{|c|}{ Haplotype 2} \\
\hline Allele 1 & CT & 0.569 & 0.1118 & \pm 0.0466 \\
\hline Allele 2 & $\mathrm{TC}$ & 0.386 & 0.1361 & \pm 0.0480 \\
\hline Allele 3 & $\mathrm{CC}$ & 0.044 & -0.2479 & \pm 0.0804 \\
\hline
\end{tabular}

\section{DISCUSSION}

The effect of the haplotype that consisted of two SNPs located in the FABP4 gene was significant $(\mathrm{P}<0.05)$, suggesting that these polymorphisms exert a direct effect on sexual precocity. The haplotype has three alleles (Table 4), one practically neutral and the other two with opposite signs. A third SNP in the same gene, but in LD with the two SNPs, had no significant effect on the trait. We found no studies in the literature reporting direct effects of FABP4 polymorphisms on sexual precocity. However, Hoashi et al. (2008) observed a significant effect of polymorphisms in this gene on the percentage of C16:1 cholesterol. According to Nelson and Cox (2008), this compound serves as a precursor of steroid hormones that, in turn, exert direct effects on reproductive organs. Free fatty acids transported by FABP4 can be activated and oxidized to produce acetyl-CoA and NADH and part of this acetyl-CoA is used for the biosynthesis of cholesterol (Kresge et al., 2005; Nelson and Cox, 2008). Steroids produced from cholesterol modulate the differentiation, growth, and physiology of reproductive organs (Ferretti et al., 2008).

Another indirect pathway through which the FABP4 gene polymorphisms are associated with sexual precocity is the leptin signaling pathway. Studies have shown that the FABP4 gene is located within the confidence interval of some QTL detected in the region, which are involved in the regulation of serum leptin levels in mice (Ogino et al., 2003). Several studies have associated leptin with sexual precocity (Foster and Nagatani, 1999; Moore et al., 2003; Wu et al., 2005; Fernyhough et al., 2007). Interestingly, however, the leptin gene was included in the present study and we found no significant effect on the trait analyzed.

The two haplotypes found on chromosome 6 in the region of the PPP $3 C A$ gene, which consisted of four and two SNPs, respectively, had a significant effect $(\mathrm{P}<0.05)$ on sexual precocity. Haplotype 1 has four alleles (Table 5), two with positive signs and two with negative signs. Haplotype 2 has three alleles (Table 5), two with a positive sign and the third, which showed the largest average effect, with a negative sign. The remaining 66 SNPs in this gene that were studied separately or formed haplotypes exerted no significant effect on sexual precocity.

There are no studies in the literature associating the PPP3CA gene with male or female sexual precocity. However, Martin et al. (2007) found that inactivation of this gene 
causes problems in the development of the testis in mice, with the observation of a reduction in the number of mature spermatids. The authors concluded that this gene is critically important for spermatogenesis and development of the testis. However, we found no studies associating this gene with female reproductive traits.

The PPP $3 C A$ gene has been shown to be involved in the differentiation of perimuscular pre-adipocytes in cattle (Taniguchi et al., 2008). Pre-adipocytes are able to differentiate into mature adipocytes, which are responsible for the storage of fat (Frayn et al., 2003). In addition, the differentiation of pre-adipocytes into mature adipocytes is associated with an increase of IGF-1 levels in the organism. Studies indicate that the gene encoding IGF-1 is related to sexual precocity (Islam et al., 2009; Micke et al., 2010). The $I G F-1$ gene was also considered to be a candidate gene in the present study, but no significant effect on the trait of interest was observed.

The FABP4 and PPP3CA genes influence sexual precocity, and therefore, may be used for the development of SNP panels in selection programs designed to improve sexual precocity in Nellore cattle.

\section{ACKNOWLEDGMENTS}

The authors thank the state funding agency Fundação de Amparo à Pesquisa do Estado de São Paulo (FAPESP, Grant \#2009/16118-5) for financial support and Conselho Nacional de Desenvolvimento Científico e Tecnológico $(\mathrm{CNPq})$ for the fellowship granted to the first author.

\section{REFERENCES}

Alencar MM, Costa JL and Correa LA (1987). Desempenho reprodutivo de fêmeas das raças canchim e nelore. Pesq. Agropec. Bras. 22: 753-758.

Anualpec (2013). Anuário da Pecuária Brasileira. 19th edn. FNP Consultoria.

Barrett JC, Fry B, Maller J and Daly MJ (2005). Haploview: analysis and visualization of LD and haplotype maps. Bioinformatics 21: 263-265.

Boligon AA, Baldi F and de Albuquerque LG (2011). Genetic parameters and relationships between growth traits and scrotal circumference measured at different ages in Nellore cattle. Genet. Mol. Biol. 34: 225-230.

Chan EK, Nagaraj SH and Reverter A (2010). The evolution of tropical adaptation: comparing taurine and zebu cattle. Anim. Genet. 41: 467-477.

de los Campos G, Gianola D and Allison DB (2010). Predicting genetic predisposition in humans: the promise of wholegenome markers. Nat. Rev. Genet. 11: 880-886.

Espigolan R, Baldi F, Boligon AA, Souza FR, et al. (2013). Study of whole genome linkage disequilibrium in Nellore cattle. BMC Genomics 14: 305.

Fernyhough ME, Okine E, Hausman G, Vierck JL, et al. (2007). PPARgamma and GLUT-4 expression as developmental regulators/markers for preadipocyte differentiation into an adipocyte. Domest. Anim. Endocrinol. 33: 367-378.

Ferretti G, Ferranti C, Crovella T, Fiori M, et al. (2008). Simultaneous analysis of 17alpha-estradiol and 17beta-estradiol in bovine serum by liquid chromatography-tandem mass spectrometry. J. Chromatogr. B Analyt. Technol. Biomed. Life Sci. 871: 135-140.

Foster DL and Nagatani S (1999). Physiological perspectives on leptin as a regulator of reproduction: role in timing puberty. Biol. Reprod. 60: 205-215.

Fortes MR, Snelling WM, Reverter A, Nagaraj SH, et al. (2012). Gene network analyses of first service conception in Brangus heifers: use of genome and trait associations, hypothalamic-transcriptome information, and transcription factors. J. Anim. Sci. 90: 2894-2906.

Frayn KN, Karpe F, Fielding BA, Macdonald IA, et al. (2003). Integrative physiology of human adipose tissue. Int. J. Obes. Relat. Metab. Disord. 27: 875-888.

Gabriel SB, Schaffner SF, Nguyen H, Moore JM, et al. (2002). The structure of haplotype blocks in the human genome. Science 296: 2225-2229. 
GenBank (2014). Available at [http://www.ncbi.nlm.nih.gov/gene/]. Accessed May 1, 2014.

Hastings N, Donn S, Derecka K, Flint AP, et al. (2006). Polymorphisms within the coding region of the bovine luteinizing hormone receptor gene and their association with fertility traits. Anim. Genet. 37: 583-585.

Hill WG and Robertson A (1968). Linkage disequilibrium in finite populations. Theor. Appl. Genet. 38: 226-231.

Hoashi S, Hinenoya T, Tanaka A, Ohsaki H, et al. (2008). Association between fatty acid compositions and genotypes of FABP4 and LXR-alpha in Japanese black cattle. BMC Genet. 9: 84.

Illumina Technical Support (2006). "TOP/BOT" Strand and "A/B" allele. Available at [http://www.illumina.com/ documents/products/technotes/technote_topbot.pdf].

Islam KK, Vinsky M, Crews RE, Okine E, et al. (2009). Association analyses of a SNP in the promoter of IGF1 with fat deposition and carcass merit traits in hybrid, Angus and Charolais beef cattle. Anim. Genet. 40: 766-769.

Kaplowitz PB (2008). Link between body fat and the timing of puberty. Pediatrics 121 (Suppl 3): S208-S217.

Kresge N, Simoni RD and Hill RL (2005). Fritz Lipmann and the Discovery of Coenzyme A. J. Biol. Chem. 208: e18.

Lenstra JA and Bradley DG (1999). Systematics and Phylogeny of Cattle. In: The Genetics of Cattle (Fries R and Ruvinsky A, eds.). CABI publishing, New York, 15-32.

Martin LJ, Chen H, Liao X, Allayee H, et al. (2007). FK506, a calcineurin inhibitor, prevents cadmium-induced testicular toxicity in mice. Toxicol. Sci. 100: 474-485.

Matukumalli LK, Lawley CT, Schnabel RD, Taylor JF, et al. (2009). Development and characterization of a high density SNP genotyping assay for cattle. PLoS One 4: e5350.

Micke GC, Sullivan TM, Gatford KL, Owens JA, et al. (2010). Nutrient intake in the bovine during early and midgestation causes sex-specific changes in progeny plasma IGF-I, liveweight, height and carcass traits. Anim. Reprod. Sci. 121: 208-217.

Moore SS, Li C, Basarab J, Snelling WM, et al. (2003). Fine mapping of quantitative trait loci and assessment of positional candidate genes for backfat on bovine chromosome 14 in a commercial line of Bos taurus. J. Anim. Sci. 81: 1919-1925.

Nelson DL and Cox MM (2008). Lehninger Principles of Biochemistry. 5th edn. WH Freeman and Company, New York.

Ogino T, Moralejo DH, Kose H, Yamada T, et al. (2003). Serum leptin concentration is linked to chromosomes 2 and 6 in the OLETF rat, an animal model of type 2 diabetes with mild obesity. Mamm. Genome 14: 839-844.

Phocas F, Bloch C, Chapelle P and Becherel F (1998). Developing a breeding objective for a French purebred beef cattle selection programme. Livest. Product. Sci. 57: 49-65.

Sambrook J, Fritsch EF and Maniatis T (1989). Molecular Cloning: A Laboratory Manual. 2nd edn. Cold Spring Harbor Laboratory, New York.

Scheet P and Stephens M (2006). A fast and flexible statistical model for large-scale population genotype data: applications to inferring missing genotypes and haplotypic phase. Am. J. Hum. Genet. 78: 629-644.

Shiotsuki L, Silva JA, Tonhati H and Albuquerque LG (2009). Genetic associations of sexual precocity with growth traits and visual scores of conformation, finishing, and muscling in Nelore cattle. J. Anim. Sci. 87: 1591-1597.

Siiteri PK (1987). Adipose tissue as a source of hormones. Am. J. Clin. Nutr. 45: 277-282.

Silva JÁ II V, Dias LT and Albuquerque LG (2005). Genetic studies of sexual precocity of heifers in a Nellore herd. $R$. Bras. Zootechnol. 34: 1568-1572.

Souza EM, Milagres JC, Silva MA and Regazzi AJ (1995). Influências genéticas e de meio ambiente sobre a idade ao primeiro parto em rebanhos de Gir leiteiro. R. Soc. Bras. Zootechnol. 24: 926-935.

Taniguchi M, Guan LL, Zhang B, Dodson MV, et al. (2008). Gene expression patterns of bovine perimuscular preadipocytes during adipogenesis. Biochem. Biophys. Res. Commun. 366: 346-351.

Wagner IV, Sabin MA, Pfaffle RW, Hiemisch A, et al. (2012). Effects of obesity on human sexual development. Nat. Rev. Endocrinol. 8: 246-254.

Weir BS (1996). Genetic Data Analysis II: Methods for Discrete Population Genetic Data. Sinauer Association, Sunderland.

Wu XL, MacNeil MD, De S, Xiao QJ, et al. (2005). Evaluation of candidate gene effects for beef backfat via Bayesian model selection. Genetica 125: 103-113.

Zhang J, Rowe WL, Clark AG and Buetow KH (2003). Genomewide distribution of high-frequency, completely mismatching SNP haplotype pairs observed to be common across human populations. Am. J. Hum. Genet. 73: 1073-1081. 